\title{
Resveratrol induces cell cycle arrest and apoptosis in human eosinophils from asthmatic individuals
}

\author{
XIN HU ${ }^{1,2^{*}}$, JING WANG $^{3 *}$, YU XIA $^{1}$, MIHEREGULI SIMAYI $^{1}$, SYED IKRAMULLAH $^{4}$, \\ YUANBING HE ${ }^{1}$, SHIHONG CUI ${ }^{1}$, SHUANG $\mathrm{LI}^{4}$ and QIMANGULI WUSHOUER ${ }^{1}$ \\ ${ }^{1}$ Department of Respiratory Medicine, The First Affiliated Hospital of Xinjiang Medical University; \\ ${ }^{2}$ Postgraduate College of Xinjiang Medical University; ${ }^{3}$ Department of Geriatrics, \\ The First Affiliated Hospital of Xinjiang Medical University, Urumqi, Xinjiang 830011; ${ }^{4}$ Department of Medicine, \\ The Changji Branch of The First Affiliated Hospital of Xinjiang Medical University, Changji, Xinjiang 831100, P.R. China
}

Received October 9, 2015; Accepted August 15, 2016

DOI: $10.3892 / \mathrm{mmr} .2016 .5884$

\begin{abstract}
Eosinophils exert a number of inflammatory effects through the degranulation and release of intracellular mediators, and are considered to be key effector cells in allergic disorders, including asthma. In order to investigate the regulatory effects of the natural polyphenol, resveratrol, on eosinophils derived from asthmatic individuals, the cell counting Kit- 8 assay and flow cytometry analysis were used to determine cell proliferation and cell cycle progression in these cells, respectively. Cellular apoptosis was detected using annexin V-fluorescein isothiocyanate/propidium iodide double-staining. The protein expression levels of p53, p21, cyclin-dependent kinase 2 (CDK2), cyclin A, cyclin E, Bim, $\mathrm{B}$-cell lymphoma (Bcl)-2 and $\mathrm{Bcl}-2$-associated $\mathrm{X}$ protein (Bax) were measured by western blot analysis following resveratrol treatment. The results indicated that resveratrol effectively suppressed the proliferation of eosinophils from asthmatic patients in a concentration- and time-dependent manner. In addition, resveratrol was observed to arrest cell cycle progression in $\mathrm{G}_{1} / \mathrm{S}$ phase by increasing the protein expression levels of p53 and p21, and concurrently reducing the protein expression levels of CDK2, cyclin A and cyclin E. Furthermore, resveratrol treatment significantly induced apoptosis in eosinophils, likely through the upregulation of Bim and Bax protein expression levels and the downregulation of $\mathrm{Bcl}-2$ protein expression. These findings suggested that resveratrol may be a potential agent for the treatment of asthma by decreasing the number of eosinophils.
\end{abstract}

Correspondence to: Dr Qimanguli Wushouer, Department of Respiratory Medicine, The First Affiliated Hospital of Xinjiang Medical University, 137 Liyushan Road, Urumqi, Xinjiang 830011, P.R. China

E-mail: qimanguliwu@tom.com

*Contributed equally

Key words: resveratrol, asthma, apoptosis, cell cycle, eosinophils

\section{Introduction}

Asthma is a complex respiratory disease that involves the remodeling of airway tissues and chronic inflammation (1). Eosinophils are considered to be key inflammatory effector cells that are implicated in the pathogenesis of various diseases, including asthma (2). Previous studies have indicated that eosinophils exert numerous proinflammatory effects in allergic disorders through the release of various proinflammatory cytokines, chemokines and cytotoxic molecules, which may ultimately lead to the manifestation of allergic asthma $(3,4)$. Besides their recruitment and activation, an increase in the survival and a reduction in the apoptosis rate of eosinophils has been proposed as a putative mechanism that accounts for the accumulation of inflammatory cells in allergic asthma (5). Currently, inhaled corticosteroids are the mainstay pharmacotherapy for asthma. The broad anti-inflammatory effects of these agents are divided into delayed actions through alterations in protein expression, and rapid actions probably through the membrane-bound glucocorticoid receptor and direct interaction with the airway vasculature. However, a small number of asthmatic patients do not respond well to inhaled corticosteroids. In addition, side-effects of corticosteroids include glaucoma, osteoporosis, growth retardation in children, wound healing and metabolic effects. Therefore, in order to improve the therapeutic strategies for patients with allergic inflammation, including asthma, the development of novel agents that inhibit eosinophil accumulation and survival is required.

Resveratrol (3,5,4'-trans-trihydroxystilbene) is a natural polyphenol and phytoestrogen found in peanuts, mulberries and grapes (Fig. 1A) (6,7). An increasing number of previous studies have indicated that resveratrol possesses a variety of pharmacological properties, including antioxidant (8), antiplatelet (9), anticancer (10) and anti-inflammatory activities (11). A previous study indicated that resveratrol downregulates the production of monocyte chemoattractant protein- 1 by endothelial cells, which is a key mediator that stimulates the infiltration of inflammatory cells into the lungs, through the inhibition of $\mathrm{p} 38$ mitogen-activated protein kinase activation in a rat model of acute pulmonary thromboembolism (12). 
Previously, it was reported that resveratrol notably inhibited the proliferation of fibroblasts from human hypertrophic scars, and decreased collagen expression in these cells (13). However, the effect of resveratrol on the proliferation and survival of human eosinophils isolated from asthmatic patients remains unclear. Based on the various biological activities of resveratrol, particularly its anti-inflammatory properties, the present study hypothesized that resveratrol may regulate the survival and apoptosis of human eosinophils. The results of the present study demonstrated an inhibitory effect of resveratrol on eosinophils from asthmatic patients through the prevention of cell cycle progression and the induction of apoptosis.

\section{Materials and methods}

Chemicals and reagents. Resveratrol was obtained from Sigma-Aldrich (EMD Millipore, Billerica, MA, USA) and was dissolved in dimethylsulfoxide (DMSO). Resveratrol was subsequently diluted with RPMI-1640 medium (Clonetics Corporation, San Diego, CA, USA) when used to treat cells in culture. The final concentration of DMSO was maintained at $<0.1 \%$ in all cell culture experiments. At this concentration, no obvious effects on cell growth were observed.

Ethical approval. The present study was approved by the Human Research and Ethics Committee of The First Affiliated Hospital of Xinjiang Medical University (Xinjiang, China). Written informed consent was obtained from a total of 10 asthma patients (6 male, aged 25-30 years; 4 female, aged 20-30 years) that were recruited to the study.

Eosinophil purification and culture. Human eosinophils were purified and cultured as described previously (14). Briefly, eosinophils were purified from peripheral blood obtained from the asthmatic patients using Percoll media (Sigma-Aldrich; EMD Millipore) and density-gradient centrifugation was used to separate the mononuclear cells from granulocytes. The lysis buffer (Beijing Solarbio Science \& Technology Co., Ltd., Beijing, China) containing erythrocytes was subsequently removed, and purification of eosinophils by negative selection was performed with CD16 immunomagnetic microbeads (catalog no. 130-045-701, Miltenyi Biotec GmbH, Bergisch Gladbach, Germany) was performed. Purified eosinophils were cultured in RPMI-1640 medium supplemented with $10 \%$ fetal calf serum at $37^{\circ} \mathrm{C}$ in $5 \%(\mathrm{v} / \mathrm{v}) \mathrm{CO}_{2}$. The purity of eosinophils was assessed by staining blood smears with Hemacolor Rapid Staining reagent (Ocon Chemicals Ltd., Cork, Ireland), and was $>98 \%$. The viability of esosinophils was evaluated by trypan blue staining and was $>98 \%$.

Cell proliferation assay. The effect of resveratrol on the proliferation of eosinophils was determined using the Cell Counting Kit-8 (CCK8; Sigma-Aldrich; EMD Millipore). Briefly, eosinophils at passage 4 were seeded into 96 -well plates at a density of $1 \times 10^{5}$ cells/well and incubated at $37^{\circ} \mathrm{C}$ overnight. The cells were subsequently treated with $0,20,40$, 80,160 or $320 \mu \mathrm{M}$ resveratrol for 24,48 and $72 \mathrm{~h}$ before $10 \mu \mathrm{l}$ CCK8 solution was added to each well. Following incubation for $4 \mathrm{~h}$ at $37^{\circ} \mathrm{C}$, the plates were read at $570 \mathrm{~nm}$ using an automated spectrophotometric plate reader (PerkinElmer,
Inc., Waltham, MA, USA). Experiments were performed three times.

Cell cycle analysis. Purified eosinophils were seeded into 6 -well plates at a density of $2 \times 10^{5}$ cells/well. After $12 \mathrm{~h}$, the cells were treated with 0,80 or $160 \mu \mathrm{M}$ resveratrol for 24 and $48 \mathrm{~h}$ before they were collected by centrifugation at 1,000 $\mathrm{xg}$ for $5 \mathrm{~min}$, at $4^{\circ} \mathrm{C}$ and washed with phosphate-buffered saline. The cells were subsequently fixed in $75 \%$ ethanol for $2 \mathrm{~h}$, resuspended in $1 \mathrm{ml}$ staining buffer (Beyotime Institute of Biotechnology, Shanghai, China) containing $10 \mu \mathrm{g} / \mathrm{ml}$ RNase A for $30 \mathrm{~min}$ and were subsequently stained with $15 \mu \mathrm{g} / \mathrm{ml}$ propidium iodide (PI) for $30 \mathrm{~min}$. The cells were analyzed using a flow cytometer (BD Biosciences, Franklin Lakes, NJ, USA) to determine cell cycle progression.

Detection of apoptosis by flow cytometry. Eosinophils were seeded into 6-well plates at a density of $2 \times 10^{5}$ cells/well. After $12 \mathrm{~h}$, the cells were treated with 0,80 or $160 \mu \mathrm{M}$ resveratrol for $48 \mathrm{~h}$, and were collected and washed as before. The cells were subsequently labeled with annexin V-fluorescein isothiocyanate (FITC)/PI and detected using a flow cytometer with CellQuest Pro software version 5.1 (BD Biosciences). The number of apoptotic cells, including those undergoing early apoptosis (annexin $\mathrm{V}$-FITC ${ }^{+} / \mathrm{PI}^{-}$), late apoptosis (annexin $\mathrm{V}$-FITC ${ }^{+} / \mathrm{PI}^{+}$) and necrosis (annexin $\mathrm{V}$-FITC ${ }^{+} / \mathrm{PI}^{+}$), were expressed as a percentage of the total number of cells.

Western blot analysis. After eosinophils were treated with various doses of resveratrol $(0,80$ and $160 \mu \mathrm{M})$, the cells were lysed, and the total protein was extracted and collected, as described previously (7). The protein concentration was determined using a bicinchoninic acid assay. A total of $20 \mu \mathrm{g}$ protein from each sample was separated using a 10\% SDS-PAGE gel. The proteins were subsequently transferred onto a polyvinylidene difluoride membrane. The membrane was then blocked in Tris-buffered saline-Tween-20 (TBST; pH 7.4; $1.5 \mathrm{M} \mathrm{NaCl}$; $20 \mathrm{mM}$ Tris- $\mathrm{HCl} ; 0.05 \%$ Tween-20) containing $5 \%(\mathrm{w} / \mathrm{v})$ non-fat milk for $2 \mathrm{~h}$ at room temperature. The membrane was subsequently incubated overnight at $4^{\circ} \mathrm{C}$ with the following rabbit primary antibodies: Anti-cyclin-dependent kinase 2 (CDK2; 1:1,000; catalog no. ab32147) and anti-cyclin A (1:1,000; catalog no. ab181591), purchased from Abcam (Shanghai, China); and anti-p53 (1:1,000; catalog no. 2527), anti-p21 (1:1,000; catalog no. 2947), anti-cyclin E (1:1,000; catalog no. 20,808), anti-Bim (1:800; catalog no. 2933), anti-Bax (1:800; catalog no. 5023), anti-Bcl-2 (1:800; catalog no. 4223) and anti-GAPDH (1:500; catalog no. 5174), purchased from Cell Signaling Technology, Danvers, USA. After washing three times with TBST, the membranes were incubated with an anti-rabbit peroxidase-conjugated secondary antibody (1:800; catalog no. 611-7302; Rockland Immunochemicals, Inc., Pottstown, PA, USA) at room temperature for $1 \mathrm{~h}$. Protein bands were visualized with an enhanced chemiluminescence reagent (Wuhan Boster Biological Technology, Ltd., Wuhan, China) and detected using a LAS-3000 Luminescent Imaging System (Fujifilm, Tokyo, Japan).

Statistical analysis. The data are expressed as the mean \pm standard deviation, and statistical analysis was performed using 
Table I. Effect of resveratrol on the cell cycle distribution of eosinophils.

\begin{tabular}{cccccccc}
\hline & \multicolumn{3}{c}{24 h incubation } & & \multicolumn{3}{c}{48 h incubation } \\
\cline { 2 - 3 } Resveratrol $(\mu \mathrm{M})$ & $\mathrm{G}_{1}(\%)$ & $\mathrm{S}(\%)$ & $\mathrm{G}_{2} / \mathrm{M}(\%)$ & & $\mathrm{G}_{1}(\%)$ & $\mathrm{S}(\%)$ & $\mathrm{G}_{2} / \mathrm{M}(\%)$ \\
\hline 0 & $43.25 \pm 1.41$ & $35.97 \pm 1.28$ & $20.18 \pm 1.72$ & & $49.27 \pm 1.53$ & $33.29 \pm 1.81$ & $17.46 \pm 1.73$ \\
80 & $52.86 \pm 1.65^{\mathrm{a}}$ & $30.51 \pm 1.69^{\mathrm{a}}$ & $18.34 \pm 1.53$ & & $59.63 \pm 2.75^{\mathrm{a}}$ & $25.52 \pm 2.08^{\mathrm{a}}$ & $14.25 \pm 2.07$ \\
160 & $59.18 \pm 1.49^{\mathrm{b}}$ & $25.94 \pm 1.38^{\mathrm{b}}$ & $15.76 \pm 1.25^{\mathrm{a}}$ & & $66.71 \pm 1.29^{\mathrm{b}}$ & $20.27 \pm 1.54^{\mathrm{b}}$ & $13.27 \pm 1.09^{\mathrm{a}}$
\end{tabular}

Eosinophils purified from asthmatic subjects were exposed to 0,80 or $160 \mu \mathrm{M}$ resveratrol for 24 and $48 \mathrm{~h}$, and cell cycle progression was subsequently measured using flow cytometry. The data are presented as the mean \pm standard deviation of three experiments. ${ }^{\text {a }}<0.05$ and ${ }^{\mathrm{b}} \mathrm{P}<0.01$ vs. untreated $(0 \mu \mathrm{M}$ resveratrol $)$ controls at each time point.

SPSS software (version 13.0; SPSS, Inc., Chicago, IL, USA). Differences between two groups were analyzed using the Student's $t$-test. $\mathrm{P}<0.05$ was considered to indicate a statistically significant difference.

\section{Results}

Resveratrol inhibits the proliferation of eosinophils. In order to investigate the effects of resveratrol on the eosinophil cell growth, purified eosinophils were treated with various concentrations of resveratrol $(0,20,40,80,160$ or $320 \mu \mathrm{M})$ for 24 , 48 and $72 \mathrm{~h}$. The results of CCK8 assay demonstrated that resveratrol effectively inhibited the proliferation of eosinophils in a dose- and time-dependent manner (Fig. 1B). The greatest reduction in eosinophil proliferation was observed using $320 \mu \mathrm{M}$ resveratrol for $72 \mathrm{~h}$.

Resveratrol induces cell cycle arrest in eosinophils. To investigate the effects of resveratrol on cell cycle progression, eosinophils were exposed to 0,80 or $160 \mu \mathrm{M}$ of resveratrol for 24 and $48 \mathrm{~h}$, and the cell cycle distribution profiles were determined using a flow cytometer. Compared with untreated controls, the percentage of eosinophils in $\mathrm{G}_{1}$ phase was increased, while the percentage of cells in $S$ and $G_{2} / M$ phases was decreased (Table I). These results suggested that resveratrol treatment may arrest the cell cycle progression of eosinophils in $\mathrm{G}_{1}$ phase.

Previous studies have suggested that the p53 gene serves an important role in the regulation of cell cycle progression (15-17). Therefore, the protein expression levels of p53 and its downstream target gene p21, as well as CDK2, cyclin A and cyclin $\mathrm{E}$ cell cycle mediators were investigated following exposure of eosinophils to 0,80 or $160 \mu \mathrm{M}$ resveratrol for $48 \mathrm{~h}$. Western blot analysis demonstrated that the protein expression levels of $\mathrm{p} 53(\mathrm{P}=0.0378 ; \mathrm{P}=0.0085)$, and $\mathrm{p} 21(\mathrm{P}=0.0327$; $\mathrm{P}=0.0054)$ were significantly increased following treatment with 80 and $160 \mu \mathrm{M}$ resveratrol when compared with untreated controls (Fig. 2). By contrast, the protein expression levels of CDK2 ( $\mathrm{P}=0.0342 ; \mathrm{P}=0.0034)$, cyclin $\mathrm{A}(\mathrm{P}=0.0476 ; \mathrm{P}=0.0085)$, and cyclin $\mathrm{E}(\mathrm{P}=0.0401 ; \mathrm{P}=0.0072)$ were significantly reduced following exposure to 80 and $160 \mu \mathrm{M}$ resveratrol compared with the untreated controls.

Resveratrol induces apoptosis in eosinophils. In order to investigate whether the inhibitory effect of resveratrol on

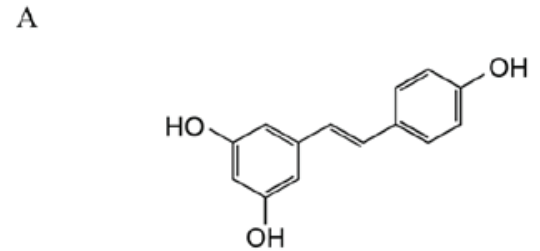

Chemical structure of resveratrol

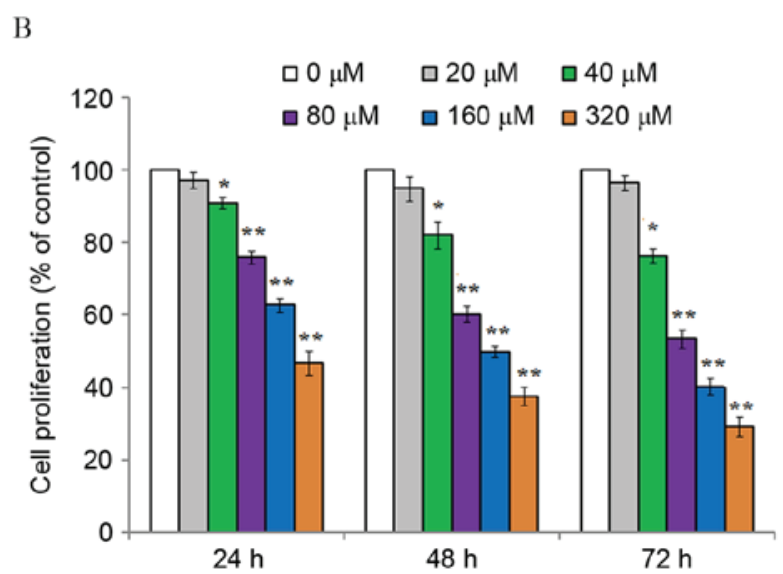

Figure 1. Effect of resveratrol on the proliferation of eosinophils derived from patients with asthma. (A) The chemical structure of resveratrol. (B) The effects of resveratrol on eosinophil proliferation was determined using a cell counting Kit- 8 assay. The results indicated that the proliferation of eosinophils was inhibited upon exposure to various doses of resveratrol for 24,48 and $72 \mathrm{~h}$. The data are presented as the mean \pm standard deviation $(n=3$; ${ }^{*} \mathrm{P}<0.05$ and ${ }^{* *} \mathrm{P}<0.01$ vs. the untreated control at each time point).

eosinophil cell proliferation was associated with induction of apoptosis, eosinophils were treated with 0,80 or $160 \mu \mathrm{M}$ resveratrol for $48 \mathrm{~h}$, and the percentage of apoptotic cells was determined using a flow cytometer. The results demonstrated that resveratrol significantly induced apoptosis in eosinophils, in a dose-dependent manner $[1.08 \pm 0.67$ vs. $23.29 \pm 3.95$ $(\mathrm{P}=0.0091)$ and $48.51 \pm 5.47 \%(\mathrm{P}=0.0036)$ following exposure to 80 and $160 \mu \mathrm{M}$ resveratrol, respectively (Fig. 3)].

To investigate the potential molecular mechanisms underlying resveratrol-induced apoptosis, the protein expression levels of pro-apoptotic Bim and Bax, and anti-apoptotic Bcl-2, were measured by western blot analysis. Compared with the untreated controls, the protein expression levels of Bim $(\mathrm{P}=0.0355 ; \mathrm{P}=0.0074)$ and $\mathrm{Bax}(\mathrm{P}=0.0406 ; \mathrm{P}=0.0081)$ were 
A

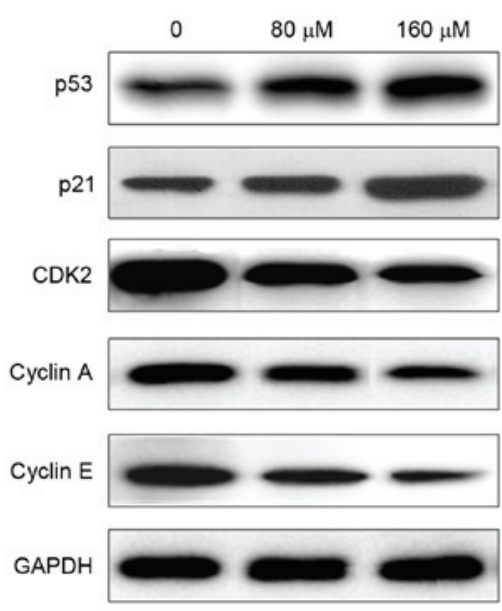

B

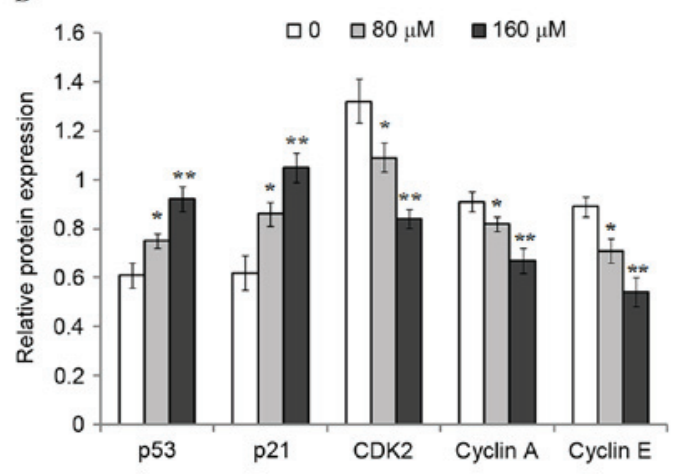

Figure 2. Effect of resveratrol on the protein expression levels of p53, p21, $\mathrm{CDK} 2$, cyclin $\mathrm{A}$ and cyclin $\mathrm{E}$ in eosinophils. The cells were treated with 0 , 80 or $160 \mu \mathrm{M}$ resveratrol for $48 \mathrm{~h}$ prior to total protein extraction and western blot analysis. (A) Representative immunoblotting images and (B) densitometric analysis of the relative protein expression levels of p53, p21, CDK2, cyclin A and cyclin E. GAPDH was used as a loading control. The data are presented as the mean \pm standard deviation $\left(n=3 ;{ }^{*} \mathrm{P}<0.05\right.$ and ${ }^{* *} \mathrm{P}<0.01$ vs. untreated controls). CDK2, cyclin-dependent kinase-2; GAPDH, glyceraldehyde 3-phosphate dehydrogenase.

increased significantly following exposure of eosinophils to 80 and $160 \mu \mathrm{M}$ resveratrol for $48 \mathrm{~h}$, whereas $\mathrm{Bcl}-2$ protein expression levels were significantly downregulated $(\mathrm{P}=0.0373$; $\mathrm{P}=0.0056$; Fig. 4).

\section{Discussion}

Asthma is a common chronic inflammatory disease, which has increased in incidence in the United States over the past two decades, and accounts for significant healthcare costs (18). Eosinophils are considered to serve a critical role in the pathogenesis of allergic asthma, since they release a variety of factors that maintain and exacerbate proinflammatory effects (4). The accumulation of eosinophils in the lungs is commonly observed in $50 \%$ of patients with allergic asthma. Eosinophil survival is considered to be prolonged in these patients due to the production of proinflammatory factors, which may explain the lack of eosinophil apoptosis in inflamed airways for several days (19). Therefore, the induction of eosinophil apoptosis may present a possible strategy for the resolution of eosinophil-induced inflammation in the treatment of allergic asthma. In the present study, resveratrol effectively inhibited the proliferation of eosinophils isolated from asthmatic patients in a dose and time-dependent manner. In addition, resveratrol significantly induced eosinophil apoptosis, likely through the upregulation of Bim and Bax protein expression and the downregulation of Bcl-2 expression.

Resveratrol is a polyphenolic natural phytoalexin found in various food products, and has antiproliferative, anti-inflammatory and immunomodulatory properties. For these reasons, resveratrol may be a potential agent for the treatment of inflammatory disorders (20). It has been reported that resveratrol attenuated oxidative stress and suppressed the inflammatory response in the diethylnitrosamine-initiated rat hepatocarcinogenesis (21). An additional study demonstrated that resveratrol inhibited the proliferation of human aortic and pulmonary aortic endothelial cells in a dose- and time-dependent manner, as well as disrupted cell cycle progression (22). These findings are consistent with the results of the present study demonstrating that resveratrol decreased the proliferation of eosinophils in a dose- and time-dependent manner. In addition, the results of the present study suggested that the antiproliferative effect of resveratrol on eosinophils may be associated with cell cycle inhibition. Following exposure of eosinophils to 80 and $160 \mu \mathrm{M}$ resveratrol, a greater percentage of cells in $\mathrm{G}_{1}$ phase, and a reduced percentage of cells in $S$ and $\mathrm{G}_{2} / \mathrm{M}$ phases were observed when compared with the untreated controls, which is similar to a previous report involving human hypertrophic scar fibroblasts (13). In order to investigate the mechanism of resveratrol-mediated cell cycle arrest in eosinophils further, the protein expression levels of p53, p21, CDK2, cyclin A and cyclin $\mathrm{E}$ were determined by western blotting. The results demonstrated that the protein expression levels of p53 and p21 were significantly decreased following resveratrol treatment. Previous studies have indicated that p53 serves an important role in determining the response of cells to different types and levels of stressful stimuli, and regulates downstream cell cycle, cell metabolism, DNA repair and apoptotic signaling pathways (23-25). In addition, p53 regulates the expression of downstream targets, including $\mathrm{p} 21$, which contributes to the modulation of cell cycle progression (26). CDK2 is a catalytic subunit of the cyclin-dependent protein kinase complex, and is essential for the $G_{1} / S$ phase transition of the cell cycle (27). In the absence of cyclin A and CDK2, apoptotic signaling pathways are induced. The results of the present study demonstrated that resveratrol treatment of eosinophils significantly downregulated the protein expression levels of CDK2, cyclin $A$ and cyclin E. The authors hypothesized that the increase in p53 and p21, and the concurrent reduction in CDK2, cyclin $\mathrm{A}$ and cyclin E protein expression levels in eosinophils, may provide an explanation for the resveratrol-mediated cell cycle arrest in $\mathrm{G}_{1} / \mathrm{S}$ phase.

It is possible that a defect in apoptosis may contribute to the chronic tissue eosinophilia associated with asthma (28). Eosinophil apoptosis is delayed in asthma, which may be partly explained by production of granulocyte macrophage colony-stimulating factor (28). In a previous study, the apoptotic index of peripheral blood eosinophils from asthmatic 
A
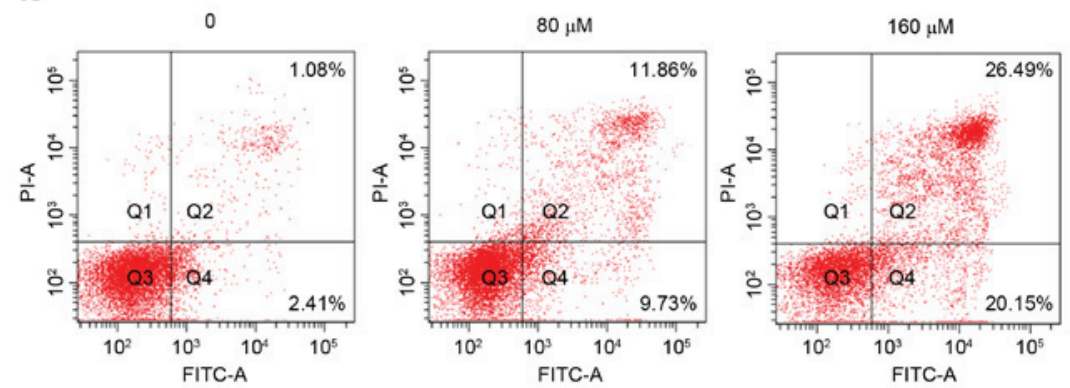

B

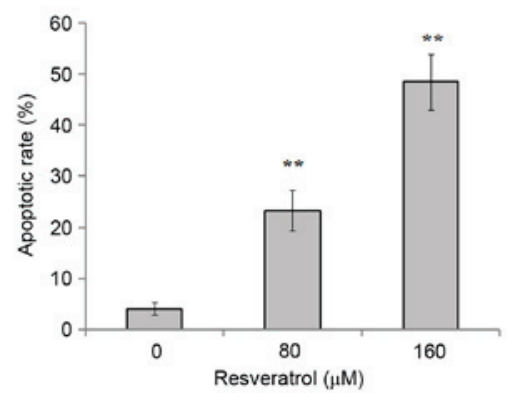

Figure 3. Effect of resveratrol on the induction of apoptosis in eosinophils. The cells were treated with 0,80 or $160 \mu \mathrm{M}$ resveratrol for $48 \mathrm{~h}$ prior to staining with annexin V-FITC and PI, and were analyzed using a flow cytometer. (A) Representative flow cytometry plots showing the percentage of cells in early apoptosis (annexin V-FITC ${ }^{+} / \mathrm{PI}$ ), late apoptosis (annexin V-FITC $/ \mathrm{PI}^{+}$) and necrosis (annexin V-FITC $/ \mathrm{PI}^{+}$). (B) The mean percentage of apoptotic eosinophils following resveratrol treatment from three individual experiments was plotted. The data are presented as the mean \pm standard deviation $\left(\mathrm{n}=3 ;{ }^{* * *} \mathrm{P}<0.01\right.$ vs. the untreated control). FITC, fluorescein isothiocyanate; PI, propidium iodide.

A

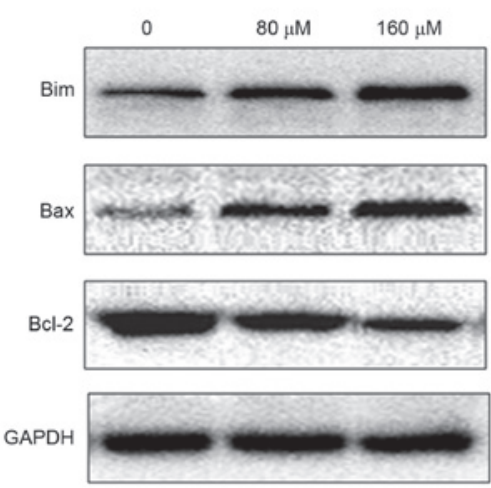

B

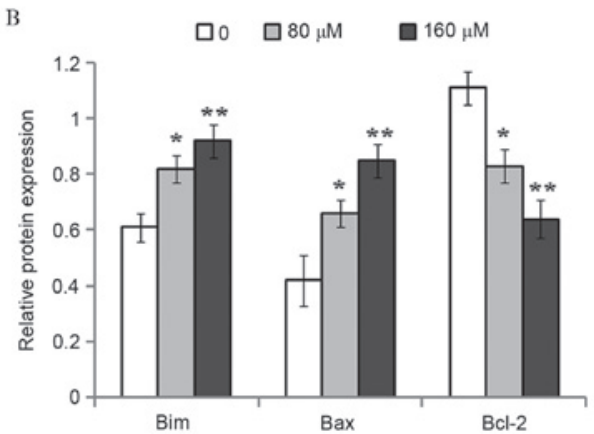

Figure 4. Effect of resveratrol on the protein expression levels of Bim, Bax and Bcl-2 in eosinophils. The cells were exposed to 0,80 or $160 \mu \mathrm{M}$ resveratrol for $48 \mathrm{~h}$, and the protein expression levels were analyzed by western blotting. (A) Representative immunoblotting images and (B) densitometric analysis of the relative protein expression levels of Bim, Bax and Bcl-2 in eosinophils, demonstrating that resveratrol upregulated the expression of pro-apoptotic Bim and Bax mediators, and downregulated anti-apoptotic Bcl-2 expression. GAPDH was used as a loading control. The data are presented as the mean \pm standard deviation $\left(\mathrm{n}=3 ;{ }^{*} \mathrm{P}<0.05\right.$ and ${ }^{* *} \mathrm{P}<0.01$ vs. untreated controls). Bcl-2, B-cell lymphoma-2; Bax, Bcl-2-associated X protein. patients and healthy volunteers was observed to be different. Eosinophils from asthmatic patients not taking steroid medication exhibited a lower apoptosis index $(0.25)$ than those from healthy control subjects (0.40) (28). In addition, eosinophils isolated from asthmatic patients not undergoing treatment with steroid medication survived for a longer period of time compared with those from healthy control subjects. The induction of eosinophil apoptosis is a current strategy used for the treatment of allergic asthma, and forms the basis of a number of available anti-asthmatic agents, including glucocorticoids, theophylline and leukotriene modifiers (19). The results of the present study demonstrated that the treatment of eosinophils with resveratrol induced apoptosis in a dose-dependent manner. Further investigation demonstrated that the expression levels of proapoptotic Bim and Bax proteins were upregulated, while the expression of the antiapoptotic protein $\mathrm{Bcl}-2$ was reduced following exposure to resveratrol. This may explain the observed increase in the proportion of apoptotic eosinophils following exposure to resveratrol.

In conclusion, the results of the present study demonstrated that resveratrol treatment effectively suppressed the proliferation of eosinophils from asthmatic patients. In addition, resveratrol exposure increased the percentage of eosinophils in $\mathrm{G}_{1}$ phase, and reduced the percentage of cells in $\mathrm{S}$ and $\mathrm{G}_{2} / \mathrm{M}$ phases, potentially through the upregulation of p53 and p21 and the downregulation of CDK2, cyclin A and cyclin E protein expression levels. Furthermore, resveratrol induced apoptosis in eosinophils, likely through increasing $\mathrm{Bim}$ and Bax protein expression and reducing $\mathrm{Bcl}-2$ protein expression levels. These findings suggested that resveratrol may be a potential candidate for the treatment of asthma. 


\section{Acknowledgements}

The authors would like to thank Dr Peter Rancourt (Doküz Eylul University, Izmir, Turkey) for proofreading the manuscript. The present study was partly supported by the National Natural Science Foundation of China (grant nos. 81160004 and 81100026).

\section{References}

1. Haj-Salem I, Fakhfakh R, Bérubé JC, Jacques E, Plante S, Simard MJ, Bossé Y and Chakir J: MicroRNA-19a enhances proliferation of bronchial epithelial cells by targeting TGF $\beta$ R2 gene in severe asthma. Allergy 70: 212-219, 2015.

2. Hogan SP, Rosenberg HF, Moqbel R, Phipps S, Foster PS, Lacy P, Kay AB and Rothenberg ME: Eosinophils: Biological properties and role in health and disease. Clin Exp Allergy 38: 709-750, 2008

3. Lemière C, Ernst P, Olivenstein R, Yamauchi Y, Govindaraju K, Ludwig MS, Martin JG and Hamid Q: Airway inflammation assessed by invasive and noninvasive means in severe asthma: Eosinophilic and noneosinophilic phenotypes. J Allergy Clin Immunol 118: 1033-1039, 2006.

4. Wong CK, Hu S, Leung KM, Dong J, He L, Chu YJ, Chu IM, Qiu HN, Liu KY and Lam CW: NOD-like receptors mediated activation of eosinophils interacting with bronchial epithelial cells: A link between innate immunity and allergic asthma. Cell Mol Immunol 10: 317-329, 2013.

5. Nutku E, Aizawa H, Hudson SA and Bochner BS: Ligation of Siglec-8: A selective mechanism for induction of human eosinophil apoptosis. Blood 101: 5014-5020, 2003.

6. Alexander NS, Hatch N, Zhang S, Skinner D, Fortenberry J, Sorscher EJ and Woodworth BA: Resveratrol has salutary effects on mucociliary transport and inflammation in sinonasal epithelium. Laryngoscope 121: 1313-1319, 2011.

7. Hiroto Y, Tadokoro K, Tsuda T, Nakazono E, Ohnaka K, Takayanagi R, Hamasaki N and Tsuda H: Resveratrol, a phytoestrogen found in red wine, down-regulates protein $\mathrm{S}$ expression in HepG2 cells. Thromb Res 127: e1-e7, 2011.

8. Yao J, Wang JY, Liu L, Li YX, Xun AY, Zeng WS, Jia CH, Wei XX, Feng JL, Zhao L and Wang LS: Anti-oxidant effects of resveratrol on mice with DSS-induced ulcerative colitis. Arch Med Res 41: 288-294, 2010.

9. Pervaiz S and Holme AL: Resveratrol: Its biologic targets and functional activity. Antioxid Redox Signal 11: 2851-2867, 2009.

10. Bishayee A, Politis T and Darvesh AS: Resveratrol in the chemoprevention and treatment of hepatocellular carcinoma. Cancer Treat Rev 36: 43-53, 2010.

11. Glehr M, Fritsch-Breisach M, Lohberger B, Walzer SM, Moazedi-Fuerst F, Rinner B, Gruber G, Graninger W, Leithner A and Windhager R: Influence of resveratrol on rheumatoid fibroblast-like synoviocytes analysed with gene chip transcription. Phytomedicine 20: 310-318, 2013.

12. Chun C, Yang W, Xueding C, Qi Z, Xiaoying H, Honglei X, Fangyou Y, Chan C, Yuanyuan L, Weixi Z, et al: Resveratrol downregulates acute pulmonary thromboembolism-induced pulmonary artery hypertension via p38 mitogen-activated protein kinase and monocyte chemoattractant protein-1 signaling in rats. Life Sci 90: 721-727, 2012.
13. Zeng G, Zhong F, Li J, Luo S and Zhang P: Resveratrol-mediated reduction of collagen by inhibiting proliferation and producing apoptosis in human hypertrophic scar fibroblasts. Biosci Biotechnol Biochem 77: 2389-2396, 2013.

14. Na HJ, Hudson SA and Bochner BS: IL-33 enhances Siglec-8 mediated apoptosis of human eosinophils. Cytokine 57: 169-174, 2012.

15. Kheirollahi M, Mehr-Azin M, Kamalian N and Mehdipour P: Expression of cyclin D2, P53, Rb and ATM cell cycle genes in brain tumors. Med Oncol 28: 7-14, 2011.

16. Fischer M, Quaas M, Steiner L and Engeland K: The p53-p21-DREAM-CDE/CHR pathway regulates G2/M cell cycle genes. Nucleic Acids Res 44: 167-174, 2016.

17. Lukin DJ, Carvajal LA, Liu WJ, Resnick-Silverman L and Manfredi JJ: P53 promotes cell survival due to the reversibility of its cell-cycle checkpoints. Mol Cancer Res 13: 16-28, 2015.

18. Yang ZC, Yi MJ, Ran N, Wang C, Fu P, Feng XY, Xu L and $\mathrm{Qu} \mathrm{ZH}$ : Transforming growth factor- $\beta 1$ induces bronchial epithelial cells to mesenchymal transition by activating the Snail pathway and promotes airway remodeling in asthma. Mol Med Rep 8: 1663-1668, 2013.

19. Ilmarinen $\mathrm{P}$ and Kankaanranta $\mathrm{H}$ : Eosinophil apoptosis as a therapeutic target in allergic asthma. Basic Clin Pharmacol Toxicol 114: 109-117, 2014.

20. Tian J, Chen JW, Gao JS, Li L and Xie X: Resveratrol inhibits TNF- $\alpha$-induced IL-1 $\beta$, MMP-3 production in human rheumatoid arthritis fibroblast-like synoviocytes via modulation of PI3kinase/Akt pathway. Rheumatol Int 33: 1829-1835, 2013.

21. Bishayee A, Barnes KF, Bhatia D, Darvesh AS and Carroll RT: Resveratrol suppresses oxidative stress and inflammatory response in diethylnitrosamine-initiated rat hepatocarcinogenesis. Cancer Prev Res 3: 753-763, 2010.

22. Hsieh TC, Lu X, Guo J and Wu JM: Differential regulation of proliferation, cell cycle control and gene expression in cultured human aortic and pulmonary artery endothelial cells by resveratrol. Int J Mol Med 26: 743-749, 2010

23. Kruse JP and Gu W: Modes of p53 regulation. Cell 137: 609-622, 2009.

24. Jiang H, Xu Z, Zhong P, Ren Y, Liang G, Schilling HA, Hu Z, Zhang Y, Wang X, Chen S, et al: Cell cycle and p53 gate the direct conversion of human fibroblasts to dopaminergic neurons. Nat Commun 6: 10100, 2015.

25. Huang X, Zhang S, Qi H, Wang Z, Chen HW, Shao J and Shen J: JMJD5 interacts with p53 and negatively regulates p53 function in control of cell cycle and proliferation. Biochim Biophys Acta 1853: 2286-2295, 2015.

26. Armstrong MJ, Stang MT, Liu Y, Gao J, Ren B, Zuckerbraun BS, Mahidhara RS, Xing Q, Pizzoferrato E and Yim JH: Interferon regulatory factor 1 (IRF-1) induces p21(WAF1/CIP1) dependent cell cycle arrest and p21(WAF1/CIP1) independent modulation of survivin in cancer cells. Cancer Lett 319: $56-65,2012$

27. Fei Q, Guo C, Xu X, Gao J,Zhang J, Chen T and Cui D: Osteogenic growth peptide enhances the proliferation of bone marrow mesenchymal stem cells from osteoprotegerin-deficient mice by CDK2/cyclin A. Acta Biochim Biophys Sin (Shanghai) 42: 801-806, 2010.

28. Kankaanranta H, Lindsay MA, Giembycz MA, Zhang X, Moilanen E and Barnes PJ: Delayed eosinophil apoptosis in asthma. J Allergy Clin Immunol 106: 77-83, 2000. 